\title{
Daily use of $\beta$ carotene supplements did not prevent skin cancer, but daily sunscreen use reduced the incidence of squamous cell carcinomas
}

Green A, Williams $G$, Neale $R$, et al. Daily sunscreen application and betacarotene supplementation in prevention of
basal-cell and squamous-cell carcinomas of the skin: a randomised controlled trial. Lancet 1999 Aug 28;354:723-9.

QUESTION: In healthy adults, does the daily use of sunscreen or $\beta$ carotene

supplements prevent skin cancer?

\section{Design}

Randomised (allocation concealed*), blinded (outcome assessor),* placebo controlled trial with a $2 \times 2$ factorial design and 4.5 year follow up.

\section{Setting}

Subtropical Queensland, Australia.

\section{Participants}

1621 participants (mean age $49 \mathrm{y}, 56 \%$ women) who were 20 to 69 years of age when they completed a skin cancer survey in 1986, had completed a second survey in 1992, and had a complete skin examination by a dermatologist with removal of all diagnosed tumours of the skin. Follow up was $85 \%$.

\section{Intervention}

Participants were allocated to 1 of 4 groups: daily use of sun protection factor 15 plus broad spectrum sunscreen (to cover exposed sites on head, neck, arms, and hands) and $\beta$ carotene, one $30 \mathrm{mg}$ tablet/day $(\mathrm{n}=404)$; daily sunscreen and placebo tablets $(n=408) ; \beta$ carotene alone $(n=416)$; and placebo alone $(n=393)$. Participants in the $\beta$ carotene alone or placebo alone groups were told they could continue using sunscreen at their usual discretionary rate $(74 \%$ of these adults used sunscreen $\leqslant 2 \mathrm{~d} / \mathrm{wk})$.

\section{Main outcome measures}

Person time based incidence and total tumour incidence of basal cell carcinoma or squamous cell carcinoma that was diagnosed $\geqslant 1$ year after the intervention began.

\section{Main results}

65 adults who used sunscreen daily and 63 adults who did not use sunscreen daily developed basal cell carcinoma; for squamous cell carcinoma, the respective numbers were 22 and 25 . The differences were not statistically significant (basal cell carcinoma rate ratio $1.03,95 \%$ CI 0.73 to 1.46 ; squamous cell carcinoma rate ratio 0.88 , CI 0.50 to 1.56 ). Among adults who received $\beta$ carotene supplements, 102 developed basal cell carcinoma and 40 developed squamous cell carcinoma, whereas the respective numbers for those who received placebo were 93 and 28. The differences were not statistically significant (basal cell carcinoma rate ratio 1.04 , CI 0.73 to 1.27 ; squamous cell carcinoma rate ratio 1.35 , CI 0.84 to 2.19). 22 people in sunscreen groups had 28 incident squamous cell tumours, and 25 people in control groups had 46 tumours (tumour rate ratio
0.61 , CI 0.46 to 0.81$) .45$ adults would need to use sunscreen for 4.5 years to prevent 1 squamous cell tumour. The study design had $80 \%$ power to detect a $36 \%$ difference for basal cell carcinoma and a 59\% difference for squamous cell carcinoma.

\section{Conclusions}

The daily use of $\beta$ carotene supplements did not reduce the incidence of skin cancer; the daily use of sunscreen reduced incident squamous cell tumours.

*See glossary.

\section{COMMENTARY}

The rapid increase in the incidence of skin cancer has led to greater interest in the primary medical practice role for prevention. In the absence of good data to suggest that secondary prevention (ie, early detection of melanomas or squamous or basal cell carcinomas) is worthwhile, ${ }^{1}$ it has been hoped that primary prevention (ie, avoiding sunlight) will prove effective. Previous doubts that sunscreen creams (a popular form of primary prevention) actually prevent skin cancer $^{2}$ and the possibility that they might even be harmful make a well designed intervention trial welcome.

The study by Green and colleagues showed that neither oral $\beta$ carotene nor topical sunscreen cream was harmful in the short term. The lack of evidence of benefit suggests that use of sunscreen to prevent basal cell cancer and of $\beta$ carotene to prevent both basal and squamous cell cancer is not effective. However, 2 of the 4 groups ( $\beta$ carotene alone and placebo alone groups) not assigned to use sunscreen were contaminated; $26 \%$ of these patients used sunscreen, a fact that would dilute any real effect and reduce the power of the study. Time may confirm a possible benefit of sunscreen on basal cell cancer because the authors promise to follow up the cohort.

However, the evidence for benefit of sunscreen for incident squamous cell carcinomas of the magnitude of $40 \%$ suggests that we should recommend that patients-even middle aged people-use sunscreen combined with other forms of sun avoidance in sunny climates.

Christopher Del Mar, MD, BChir, MA University of Queensland Herston, Queensland, Australia

1 Feightner JW. Prevention of skin cancer. In: the Canadian Task Force on the Periodic Health Examination. The Canadian guide to clinical preventive health care. Ottawa: Minister of Supply and Services Canada; 1994:849-59.

2 Do sunscreens prevent skin cancer? Drug Ther Bull 1998;36:49-51.
Sources of funding: National Health and Medical Research Council of Australia. Sunscreen supplied by Ross Cosmetics Australia and Woolworths Limited. $\beta$ carotene supplements and placebo supplied by Roche Vitamins and Fine Chemicals.

For correspondence: Professor A Green, Queensland Institute of Medical Research, $P O$ Royal Brisbane Hospital, Queensland 4029, Australia. Fax +61733620101. 